\title{
A Review of Integrative Medicine in Gynaecological Oncology
}

\author{
Evidenz Integrativer Medizin in der gynäkologischen Onkologie - Review
}

Authors

Affiliations
M. Kalder ${ }^{1}$, T. Müller ${ }^{2}$, D. Fischer ${ }^{3}$, A. Müller ${ }^{4}$, W. Bader ${ }^{5}$, M. W. Beckmann ${ }^{6}$, C. Brucker ${ }^{7}$, C. C. Hack ${ }^{6}$, V. Hanf ${ }^{8}$, A. Hasenburg ${ }^{9}$, A. Hein ${ }^{6}$, S. Jud ${ }^{6}$, M. Kiechle ${ }^{10}$, E. Klein ${ }^{10}$, D. Paepke ${ }^{10}$, A. Rotmann ${ }^{11}$, F. Schütz ${ }^{12}$, G. Dobos ${ }^{13}$, P. Voiß ${ }^{13}$, S. Kümmel ${ }^{13}$

The affiliations are listed at the end of the article.

\author{
Key words \\ - integrative medicine \\ - complementary medicine \\ - evidence \\ - gynecology \\ - oncology \\ Schlüsselwörter \\ - integrative Medizin \\ - Komplementärmedizin \\ - Evidenz \\ - Gynäkologie \\ - Onkologie
}

Deutsche Version unter: www.thieme-connect.de/ ejournals/gebfra

\section{Abstract \\ $\nabla$}

In recent years complementary and alternative medicine (CAM) has increasingly been the focus of international research. Numerous subsidised trials (7903) and systematic reviews (651) have been published, and the evidence is starting to be integrated into treatment guidelines. However, due to insufficient evidence and/or insufficient good quality evidence, this has mostly not translated to practice recommendations in reviews by the Cochrane collaboration gynaecology group. There is nevertheless a not insignificant number of CAM providers and users. The percentage of oncology patients who use CAM varies between 5 and $90 \%$. Doctors have been identified as the main providers of CAM. Half of gynaecologists offer CAM because of personal conviction or on suggestion from colleagues. This must be viewed in a critical light, since CAM is mostly practiced without appropriate training, often without sufficient evidence for a given method - and where evidence exists, practice guidelines are lacking and lack of safety or efficacy testing. The combination of patient demand and lucrativeness for doctors/alternative medicine practitioners, both based on supposed effectiveness CAM, often leads to its indiscriminate use with uncertain outcomes and significant cost for patients. On the other hand there is published, positive level I evidence for a number of CAM treatment forms. The aim of this article is therefore to review the available evidence for CAM in gynaecological oncology practice. The continued need for research is highlighted, as is the need to integrate practices supported by good evidence into conventional gynaecological oncology.

\section{Zusammenfassung \\ $\nabla$}

Komplementäre und alternative Medizin (CAM) stehen in den letzten Jahren zunehmend im Fokus der internationalen Forschung. Zahlreiche subventionierte Studien (7903) und systematische Reviews (651) wurden publiziert und Leitlinien beginnen, die nachgewiesene Evidenz zu integrieren. Dennoch bleiben Handlungsempfehlungen in den meisten Fällen der Reviews aus der Cochrane Collaboration Group in der Frauenheilkunde aus Mangel an ausreichender und/oder qualitativ guter Evidenz aus. Demgegenüber steht eine nicht zu vernachlässigende Gruppe von Anwendern und Anbietern. Unter den onkologischen Patienten schwanken die Zahlen der CAMAnwendung zwischen 5 und 90\%. Als Hauptanbieter für diverse CAM-Methoden in der Onkologie wurden insbesondere Ärzte identifiziert. Die Hälfte der Frauenärzte wenden CAM aufgrund eigener Überzeugung oder durch Motivation von Kollegen an. Kritisch anzumerken ist, dass dies vielfach ohne fundierte Ausbildung, häufig bei nicht ausreichender Evidenz für die eingesetzten Methoden, fehlenden Handlungsempfehlungen bei vorhandener Evidenz und fehlendem Sicherheits- oder Wirksamkeitsnachweis durchgeführt wird. Das Zusammenspiel der Nachfrage durch Patienten und das lukrative Angebot von Ärzten und Heilpraktikern, basierend auf der vermuteten Wirksamkeit, führen damit nicht selten zur unkritischen Anwendung mit ungewissen Folgen für den Patienten und erheblichen Kosten. Für einige Therapieformen liegen dagegen publizierte, positive Level-I-Evidenz beinhaltende Ergebnisse vor, sodass Ziel dieses Reviews ist, die vorhandene Evidenz zur CAM in der gynäkologischen Onkologie darzustellen, den weiterhin bestehenden Forschungsbedarf aufzuzeigen und auf den Sinn der Integration von CAM-Methoden mit guter Evidenz in die konventionelle Medizin im Bereich der gynäkologischen Onkologie hinzuweisen. 


\section{Introduction}

\section{$\nabla$}

The term "integrative medicine" has become increasingly established in both Anglo-American and German-speaking countries. It implies integration of scientifically tested complementary medicine practices into established evidence-based medicine. The following quotes from the literature from 2006 and 2012 illustrate the term: "Over time, some complementary therapies are proven safe and effective. These become integrated into mainstream care producing integrative oncology, a synthesis of the best of mainstream cancer treatment and rational, databased, adjunctive complementary therapies" [1].

"Integrative oncology combines the best practices of conventional and complementary oncology, uniting them in one, holistic concept. With the awareness that the two therapeutic methods may occasionally interfere with each other, the best solution is aimed at" [2].

According to the Working Group for Integrative Medicine (AGIMed), integrative medicine should identify practices in the complementary and alternative medicine spectrum (CAM) that are supported by good evidence from convincing studies, and that seem suited to expand the conventional medical portfolio [3]. The Gynaecological Oncology Working Group (AGO) guidelines on breast cancer treatment have integrated complimentary practices since 2002 and have contained a chapter evaluating CAM since 2011 [4].

The current AGO recommendations make a clear distinction between integrative oncology and unconventional practices. Unconventional practices are considered maverick whereas integrative oncology is understood as ancillary or alternative to scientifically based medicine [4]. Complementary practices are seen as experienced-based additions to scientific, evidence-based medicine [5].

Since its establishment in 1937, the USAs National Cancer Institute $(\mathrm{NCI})$ has been requisitioned to evaluate the various CAM methods in the treatment of cancer patients. Studies published in the 1970s and 1980s with negative results contributed to the impression being made that the $\mathrm{NCI}$ was intent only on proving a lack of effect of CAM [6].

In 1999 and 2000 White, the former director of the Office of Cancer Complementary and Alternative Medicine (OCCAM) at the $\mathrm{NCI}$, conducted 4 surveys finding that 9 to $91 \%$ of American tumour patients used CAM after diagnosis [7]. A 1998 European survey found that between 20 and $70 \%$ of the population used CAM. Over a 10 -year period $20 \%$ of EU citizens favoured CAM for medical care, $20 \%$ were regular users and $20 \%$ reported occasional use of CAM [8].

This review presents the evidence from four subareas of CAM research. We describe the CAM practices on offer as well as the demand for CAM in gynaecological oncology, country-specific CAM practice, the evidence of efficacy, safety and interactions, as well as the spectrum of CAM publications and research funding.

\section{CAM Users and Providers in Gynaecological Oncology $\nabla$}

In the late 1990s studies were published in Switzerland evaluating the motivation and expectations of CAM users [9]. Oncology patients form a large group of CAM users. Since the 1990s 40$70 \%$ of all oncology patients in Germany have used CAM, the emphasis being mostly on the complementary components of CAM, i.e. parallel to conventional treatment $[10,11]$. Oncology patients who use CAM experience a substantial individual psychological advantage, which can be considered the main motivation for its use [9].

These results agree with findings in the USA. One exception is the wider range quoted in the English literature, with CAM user rates among oncology patients between 5 and 90\% [6,11].

It is somewhat alarming that the recommendation to use CAM comes from a friend in $56 \%$ of cases, from family members in $29 \%$ and from doctors in only $1 \%$ [12]. Reasons given by patients for using CAM include consciously fighting against the cancer, physical and psychological support for the body and general well-being. In addition, $23 \%$ of those interviewed stated in an alarmingly uncritical way with respect to CAM: "might help won't hurt" [12].

Results of a survey conducted in 11 European countries in 2006 among women with breast cancer demonstrated that $45 \%$ of patients are CAM users from the time of diagnosis, and that the majority are satisfied with it. According to their own claims only $6.5 \%$ of these women did not benefit from using CAM. Young educated women were especially well represented among satisfied CAM users [13].

According to Gross et al. young women with higher education level who have metastatic breast cancer are more likely to seek out alternative medicine practitioners, and use phytotherapy more often, than older, less well educated women [13,14].

There were equal numbers of educated and uneducated women among patients with breast cancer who practiced yoga; these women had a lower Body Mass Index (BMI) [15]. Swisher et al. list previous CAM use (before cancer diagnosis), gynaecological tumour other than cervical carcinoma and annual income over $\$ 30000$ as important predictors of CAM use among patients with gynaecological tumours [16].

In the late 1990s, concurrent with studies on CAM users, first publications on the attitudes of doctors appeared describing their characteristics and opinions on the use of CAM in oncology. It was shown that doctors form the main group of practitioners offering CAM to oncology patients, not alternative health practitioners as was assumed [17-20].

Studies from different countries show that doctor's attitudes and opinions vary significantly according to nationality $[10,21]$.

As an example, oncologists in China and Taiwan recommended a combination of CAM and conventional treatment to patients with curable disease less commonly than oncologists in the USA. This finding is surprising in view of the long, nationally-based, cultural and historical CAM traditions in Asia, and since the prevalence of CAM use among tumour patients in this study was over $80 \%$ [22].

In Australia, doctors working in the field of oncology rehabilitation refer $84 \%$ of patients for CAM [23].

The requirement is therefore understandable that oncologists should be aware of potential interactions between standard prescribed treatment regimes and the CAM products patients use independently [14].

47 to $85 \%$ of women with breast cancer who used CAM did not disclose this to their treating doctors [24]. In the field of general gynaecology only $51.8 \%$ of women disclosed their use of CAM $[11,25]$.

A logical recommendation is therefore for doctors to destigmatise the use of CAM in their communication with patients [24].

Doctors should ask patients specifically about CAM usage and provide information on potential interactions, risks and the benefits of CAM practices. In this way the communication barrier be- 
tween doctors and patients, often the result of strongly differing opinions on the issue of CAM, could potentially be overcome [26].

\section{International Spectrum of Common CAM Practices}

$\nabla$

The spectrum of CAM implementation in gynaecological oncology is heterogenous. In the 1990s the 6 most common CAM practices described by doctors working in gynaeco-oncology in Germany were mistletoe, homeopathy, acupuncture, selenium substitution, vitamins and diets [27]. Homeopathy was identified as the most commonly used in paediatric oncology (Germany) [28]. Preferred CAM practice differed significantly between studies from different countries $[10,21,29,30]$. Specific CAM practices are often chosen based on their cultural background. Supoken et al. and their working group in Thailand identified Buddhist prayer (over $90 \%$ ), phytotherapy (40\%) and physical exercises (37\%) as the 3 most common CAM practices among gynaecological tumour patients [31]. Women in Turkey with metastatic breast cancer most commonly use phytotherapy followed by dietary supplements [32].

In the field of rehabilitative medicine, which is often the point of initial follow-on treatment for oncology patients, the prescription of certain CAM methods is also common. The Australian study by Mak et al. lists acupuncture (80\%), yoga (70\%) and Tai Chi $(72 \%)$ as the most common $[15,23]$.

Fasching et al. report that in Germany $50 \%$ of breast cancer patients and $44 \%$ of patients with gynaecological tumours in general use CAM. Mistletoe is used most commonly (77\%), and more often by breast cancer patients than those with other gynaecological tumours ( 74.4 vs. $67 \%$ ). Users of CAM report deterioration in their health less often (35.1 vs. 50.1\%) [33].

Older surveys have shown that preferences for CAM vary immensely even within medical specialities [34].

CAM is sometimes recommended on the basis of supposed or confirmed evidence for a specific treatment, sometimes however because conventional therapy has failed.

In this respect it is interesting to note that half of gynaecologists who prescribe or recommend CAM do so on the basis of personal conviction or following the advice of a colleague, the conviction however often being based on supposed efficacy, not evidence $[17,35]$. On the other hand $40 \%$ of interviewees recommended CAM because of the ineffectiveness of conventional therapies [27]; in view of the fact that older, more experienced gynaecological oncologists have been identified as the main practitioners offering CAM, this is presumably an expression of helplessness when reaching the limits of conventional treatment options. The recommendation to use CAM could be interpreted as an act of desperation. In our view, however, CAM should be avoided when desperation is the only motivation for its use, since in recent years increasingly helpful palliative medical options have been developed especially in the field of oncology [36].

\section{Efficacy, Safety and Interactions \\ $\nabla$}

There is very good evidence for the efficacy of sport/physical activity and nutrition in oncology. Pierce et al. demonstrated a $50 \%$ reduction in 10-year breast cancer mortality with a regular diet of fruit and vegetables (at least 5 portions or more distributed over the day) and sport/physical activity (approx. 30 minutes walking
6 days a week). This result was independent of BMI and was not achieved with either healthy diet or physical activity alone [37]. Despite increased scientific study there is nevertheless a lack of evidence proving efficacy of CAM practices and their safety for patients. Numerous publications point out this lack of evidence, the authors unanimously calling for further studies to provide evidence of safety and indication-based efficacy of the individual CAM treatments [38].

As an example, the systematic review by Bardia et al. concludes that there is a lack of multicentre studies evaluating the effects of CAM on alleviating tumour-related pain. The studies included in the review do show positive trends for some CAM practices, particularly hypnosis and acupuncture, however the level of evidence does not support any general recommendations. Prospective, randomised, multicentre trials are required whose primary endpoints are the efficacy of CAM treatments [39].

A literature search from 2010 found no evidence for efficacy or safety of herbal treatments for hot flushes among women with previous breast cancer. The use of phytooestrogen containing soya products for women with previous breast cancer is explicitly not recommended in the face of evidence of a counterproductive effect, i.e. that phytooestrogens may increase the likelihood of tumour recurrence [40].

Another relevant aspect is the research pertaining to the interference between standard treatments and alternative components of CAM. Han et al. followed breast cancer patients over a period of 10 years who had declined or delayed standard therapy in favour of alternative treatment. A substantial increase in disease progression, recurrence risk and mortality was observed. The estimated 10 year survival rate calculated in this study for patients with FIGO stage II cancer, who declined an operation, was 69.5\%. Actual survival at a median of 33 months follow-up was only $36.4 \%$. The 61 patients were on average in FIGO stage II on study inclusion, compared to FIGO IV following their alternative treatments. Han et al. recommended that these data be integrated into doctor-patient discussions, to support decision-making for individual treatments [41].

The literature contains published evidence of numerous interactions and dangers associated with CAM.

Whereas earlier publications reported reactions such as fever and severe anaphylaxis/circulatory shock following mistletoe injection, current studies show no evidence of serious events [42, 43]. A measureable improvement in quality of life has been shown for breast cancer patients on chemotherapy who received mistletoe preparations, however evidence for an effect of mistletoe on survival, local tumour control and reduction in the sideeffects of antitumour treatments was regarded overall as weak [43].

Due to interaction with oncology drugs CAM preparations can cause increased toxicity and reduced efficacy of standard oncological treatment. The phytotherapeutic agent St. John's wort, known in the treatment of depression, interacts with the cytochrome P450 isoform CYP3A4, amongst others, thus reducing the chemotherapeutically active metabolite of irinotecan by over $50 \%$. Patients treated with St. John's wort thus show a counterproductive improved tolerance of their chemotherapy through reduction in toxicity [44].

There is level 1 evidence for "mindfulness-based stress reduction training" (MBSR) for the treatment of anxiety disorders and depression in oncology patients with diverse tumours, without any of the above mentioned interactions $[45,46]$. MBSR can reduce stress-related physical and psychological symptoms (anxi- 
Table 1 Observation of the increase of publications, reviews and RCTs at the example of acupuncture and homeopathy.

\begin{tabular}{|c|c|c|c|c|c|c|c|}
\hline & \multicolumn{3}{|l|}{ 1900-1999 } & \multicolumn{3}{|l|}{$2000-2011$} & \multirow[t]{2}{*}{ Total } \\
\hline & Publications & Reviews & $\mathrm{RCT}$ & Publications & Reviews & RCT & \\
\hline Acupuncture & 7553 & 576 & 321 & 8557 & 1288 & 1582 & 16112 \\
\hline Homeopathy & 2223 & 132 & 49 & 2096 & 346 & 101 & 4296 \\
\hline
\end{tabular}

$\mathrm{RCT}=$ randomised controlled trials

ety, depression, panic attacks). Further positive effects of this form of therapy include improved quality of life, the development of coping strategies with resultant reduced fear of recurrence, and emotional stability [46].

Acupuncture is often used to reduce side effects of cancer treatment. Evidence-based indications for acupuncture treatments include chemotherapy-induced nausea and vomiting, aromatase inhibitor-induced arthralgia, fatigue and pain [4]. Acupuncture is a treatment form with a good side-effect profile when providers are appropriately trained. There are however publications reporting severe complications such as infections (bacterial meningitis, hepatitis $\mathrm{C}$, infectious endocarditis, AIDS), retroperitoneal abscess and mechanically induced pericardial effusion and cardiac tamponade [47-54]. Direct needling in the tumour area should also be avoided, to prevent tumour seeding [55]. Acupuncture is an effective treatment for side-effect reduction and improvement of quality of life in cancer patients when used with careful consideration of its indications and contraindications [56].

In a controlled, randomised trial menopausal symptoms in patients with breast cancer were reduced in both the acupuncture group and the group treated with venlafaxine. Whereas sideeffects were reported in the venlafaxine group, none were reported in the acupuncture group. In the acupuncture group the positive effect persisted after the intervention was stopped, while in the venlafaxine group symptoms worsened again two weeks after stopping treatment [57].

Ayurvedic herbal medicine products sold in Boston and produced in South Asia contained toxic concentrations of arsenic, mercury and lead [58]. In a British alternative medicine hospital a case of hepatitis B infection was caused by autohaemotherapy [59]. On the other hand accidental ingestion of homeopathic or herbal medical products by children was found to be mostly harmless over a 10 -year observation period [60].

Two studies of CAM products in breast cancer patients from 2011 (Hietala et al. in Sweden and Kang et al. in Korea) note that these products cause significant drug interactions, and that it should therefore be of clinical interest to identify potential CAM users $[61,62]$.

These results support the call for doctors to be adequately trained in the use of CAM products, and that integrative medicine find a place in oncology treatment guidelines.

A significant increase in research activity in the field of CAM extending to the study of basic principles, and with well considered question formulation, is not to be dismissed.

As an example, numerous studies provide evidence on the use of green tea extracts. Ahn et al. reported successful treatment of cervical lesions with green tea extracts and suggest a potential treatment for HPV positive patients with cervical lesions [63]. Zhang et al. were able to demonstrate that green tea extracts effectively inhibit the proliferation of leiomyoma cells, both in vitro and in vivo [64]. Kim et al. and research group recorded an inhibitory ef- fect of green tea polyphenol epifallocatechin 3 gallate on ovarian carcinoma cell lines, which may be relevant for future drug development for ovarian cancer [65]. Kakuta et al. concluded that green tea consumption is associated with decreased risk for the development of uterine corpus endometrioid adenocarcinoma [66].

Longo et a. showed that fasting two days before and one day after chemotherapy reduces treatment side effects. Healthy cells seem to react self-protectively by inhibition of their cell cycle on fasting days, thus sparing themselves the effects of the antitumour therapy. Tumour cells on the other hand lack this adaptability, their proliferative state making them vulnerable to antitumour treatment. In addition, quicker recovery of the blood cell population was observed with fasting [67-69]. The fear of weight loss while on chemotherapy is a factor that must be considered; treatment with fasting does not seem to be a method of choice, and should at the very least be evaluated in the study setting with consideration of BMI.

A current Cochrane review, fresh off the press from November 2015, describes a possible beneficial effect of cannabis-based therapy for chemotherapy induced vomiting. The authors describe the available literature on the subject (23 RCTs) as very limited [70].

\section{Number of CAM Publications and Funding $\nabla$}

A comparison of the time intervals before 1999 and between 2000 and 2011 on MEDLINE reveals an abrupt increase in CAM publications (e.g. on acupuncture and homeopathy), the increase is however accounted for by randomised controlled trials and review articles ( $\bullet$ Table 1 ).

The results of intensive research efforts (up until 30.11.2015) financed by the NCCAM include 7903 published studies ( 78 gynaecological and 145 oncological) and 651 reviews ( 7 gynaecological and 23 oncological), as well as 37 systematic reviews by the Cochrane collaboration on various topics in oncology ( 3 on breast cancer and one on colposcopy in the context of early screening) [71]. There are however few positive recommendations and the majority of Cochrane reviews on CAM in the field of gynaecology reveal questionable evidence from which no practice recommendations can be drawn [38].

The National Institute of Health (NIH) in the USA has increased its funding of CAM research incrementally from 116000 in 1999 to $124296000 \$$ in 2014 , however the amount from 2014 represents only $0.41 \%$ of NIHs total budget for 2014 (30142653000\$). In comparison the $\mathrm{NCI}$ received a budget of $4923238000 \$(16.3 \%)$ for 2014 [72]. 


\section{Future Perspective}

The economic situation in the health sector and the increased demand for CAM treatment from patients in gynaecological oncology constitute significant impulses in the continuing development of evidence-based data in this medical field in Germany. Doctors have an ethical obligation to optimise the use of resources, implementing newly acquired evidence through the integration of evidence-based CAM into conventional medicine, and counselling patients proactively about non evidence-based practices.

\section{Conflict of Interest}

$\nabla$

None.

\section{Affiliations}

${ }^{1}$ Klinik für Frauenheilkunde und Geburtshilfe, Philipps-Universität Marburg, Marburg

2 AGAPLESION Markus Krankenhaus, Abteilung für Gynäkologie und Geburtshilfe, Frankfurt am Main

${ }^{3}$ Klinik für Gynäkologie und Geburtshilfe, Klinikum Ernst von Bergmann, Potsdam

${ }^{4}$ Frauenklinik, Städtisches Klinikum Karlsruhe gGmbH, Karlsruhe

${ }^{5}$ Zentrum für Frauenheilkunde, Klinikum Bielefeld Mitte, Bielefeld

${ }^{6}$ Universitäts-Brustzentrum Franken, Frauenklinik des Universitätsklinikums Erlangen, Friedrich-Alexander Universität Erlangen-Nürnberg, Comprehensive Cancer Center Erlangen - Europäische Metropolregion Nürnberg, Nürnberg

7 Universitätsklinik für Frauenheilkunde und Geburtshilfe, Paracelsus Medizinische Privatuniversität, Nürnberg

${ }^{8}$ Frauenklinik und Brustzentrum Nathanstift, Klinikum Fürth, Fürth

${ }^{9}$ Klinik und Poliklinik für Geburtshilfe und Frauenkrankheiten, Universitätsmedizin Mainz, Mainz

${ }^{10}$ Frauenklinik des Klinikums rechts der Isar, Technische Universität München, München

11 Praxis für Frauenheilkunde, Geburtshilfe und Naturheilkunde, Rodgau

12 Universitätsfrauenklinik, Universitätsklinikum Heidelberg, Heidelberg

${ }^{13}$ Brustzentrum und Klinik für Senologie der Kliniken Essen-Mitte, Essen

\section{References}

1 Cassileth BR, Deng G. Complementary and alternative therapies for cancer. Oncologist 2004; 9: 80-89

2 Dobos GJ, Voiss P, Schwidde I et al. Integrative oncology for breast cancer patients: introduction of an expert-based model. BMC Cancer 2012; 12: 539

3 Kalder M, Müller T, Fischer D et al. Begriffsdefnition, Gründung, Ziele und Perspektiven der AG Integrative Medizin. Geburtsh Frauenheilk 2015; 75: 532-536

4 AGO. Diagnostik und Therapie primärer und metastasierter Mammakarzinome: Komplementäre Therapien. Arbeitsgemeinschaft Gynäkologische Onkologie e.V.; 2014. Online: http://www.ago-online.de/ fileadmin/downloads/leitlinien/mamma/maerz2014/de/2014D_24_ Komplementaere_Therapie.pdf; last access: 30.11 .2015

5 Hack CC, Huttner NBM, Paepke D et al. Integrative medicine in gynecologic oncology - possibilities and limits part 1. Geburtsh Frauenheilk 2013; 73: R65-R78

6 White JD. The National Cancer Institute's perspective and agenda for promoting awareness and research on alternative therapies for cancer. J Altern Complement Med 2002; 8: 545-550

7 White JD. Complementary, alternative, and unproven Methods of Cancer Treatment. In: DeVita VT, Hellman S, Rosenberg SA, eds. Cancer: Principles and Practice of Oncology. Philadelphia: Lippincott Williams \& Wilkins; 2001: 3147-3157

8 Jonas $W$. Alternative medicine and the conventional practitioner. JAMA 1998; 279: 708-709

9 Morant R, Jungi WF, Koehli C et al. [Why do cancer patients use alternative medicine?]. Schweiz Med Wochenschr 1991; 121: 1029-1034

10 Munstedt K, Kirsch K, Milch W et al. Unconventional cancer therapysurvey of patients with gynaecological malignancy. Arch Gynecol Obstet 1996; 258: 81-88
11 Von Gruenigen VE, White LJ, Kirven MS et al. A comparison of complementary and alternative medicine use by gynecology and gynecologic oncology patients. Int J Gynecol Cancer 2001; 11: 205-209

12 Molassiotis A, Fernadez-Ortega P, Pud D et al. Use of complementary and alternative medicine in cancer patients: a European survey. Ann Oncol 2005; 16: 655-663

13 Molassiotis A, Scott JA, Kearney $N$ et al. Complementary and alternative medicine use in breast cancer patients in Europe. Support Care Cancer 2006; 14: 260-267

14 Gross AM, Liu $Q$ Bauer-Wu S. Prevalence and predictors of complementary therapy use in advanced-stage breast cancer patients. J Oncol Pract 2007; 3: 292-295

15 Desai K, Bowman MA, Galantino ML et al. Predictors of yoga use among patients with breast cancer. Explore (NY) 2010; 6: 359-363

16 Swisher EM, Cohn DE, Goff BA et al. Use of complementary and alternative medicine among women with gynecologic cancers. Gynecol Oncol 2002; 84: 363-367

17 Bourgeault IL. Physicians' attitudes toward patients' use of alternative cancer therapies. CMAJ 1996; 155: 1679-1685

18 Crocetti E, Crotti N, Montella $M$ et al. Complementary medicine and oncologists' attitudes: a survey in Italy. Tumori 1996; 82: 539-542

19 Gray RE, Fitch M, Greenberg $M$ et al. Physician perspectives on unconventional cancer therapies. J Palliat Care 1997; 13: 14-21

20 Newell S, Sanson-Fisher RW. Australian oncologists' self-reported knowledge and attitudes about non-traditional therapies used by cancer patients. Med J Aust 2000; 172: 110-113

21 Ernst E, Resch KL, White AR. Complementary medicine. What physicians think of it: a meta-analysis. Arch Intern Med 1995; 155: 24052408

22 Lee RT, Hlubocky FJ, Hu JJ et al. An international pilot study of oncology physicians' opinions and practices on Complementary and Alternative Medicine (CAM). Integr Cancer Ther 2008; 7: 70-75

23 MakJC, Mak LY, Shen Q et al. Perceptions and attitudes of rehabilitation medicine physicians on complementary and alternative medicine in Australia. Intern Med J 2009; 39: 164-169

24 Saxe GA, Madlensky L, Kealey S et al. Disclosure to physicians of CAM use by breast cancer patients: findings from the Women's Healthy Eating and Living Study. Integr Cancer Ther 2008; 7: 122-129

25 Harrigan JT. Patient disclosure of the use of complementary and alternative medicine to their obstetrician/gynaecologist. J Obstet Gynaecol 2011; 31: 59-61

26 Richardson MA, Masse LC, Nanny K et al. Discrepant views of oncologists and cancer patients on complementary/alternative medicine. Support Care Cancer 2004; 12: 797-804

27 Kalder $M$, von Georgi $R$, Kullmer $U$ et al. Opinions of gynecologists on unconventional and complementary cancer therapy (UCT). Geburtsh Frauenheilk 2001; 61: 26-30

28 Langler A, Spix C, Edelhauser F et al. Use of homeopathy in pediatric oncology in Germany. Evid Based Complement Alternat Med 2011; 2011: 867151

29 Cutshall S, Derscheid D, Miers AG et al. Knowledge, attitudes, and use of complementary and alternative therapies among clinical nurse specialists in an academic medical center. Clin Nurse Spec 2010; $24: 125-$ 131

30 McKay DJ, Bentley JR, Grimshaw RN. Complementary and alternative medicine in gynaecologic oncology. J Obstet Gynaecol Can 2005; 27: $562-568$

31 Supoken A, Chaisrisawatsuk T, Chumworathayi B. Proportion of gynecologic cancer patients using complementary and alternative medicine. Asian Pac J Cancer Prev 2009; 10: 779-782

32 Yildirim Y. Patterns of the use of complementary and alternative medicine in women with metastatic cancer. Cancer Nurs 2010; 33: 194200

33 Fasching PA, Thiel F, Nicolaisen-Murmann Ket al. Association of complementary methods with quality of life and life satisfaction in patients with gynecologic and breast malignancies. Support Care Cancer 2007; 15: $1277-1284$

34 Munstedt K, Entezami A, Wartenberg A et al. The attitudes of physicians and oncologists towards unconventional cancer therapies (UCT). Eur J Cancer 2000; 36: 2090-2095

35 Baufeld K, Kullmer U, Kalder M et al. Zur Nachsorge des Endometriumkarzinoms. Geburtsh Frauenheilk 2000; 60: 423-428

36 Gaertner J, Wolf J, Hallek $M$ et al. Standardizing integration of palliative care into comprehensive cancer therapy-a disease specific approach. Support Care Cancer 2011; 19: 1037-1043 
37 Pierce JP, Stefanick ML, Flatt SW et al. Greater survival after breast cancer in physically active women with high vegetable-fruit intake regardless of obesity. J Clin Oncol 2007; 25: 2345-2351

38 Cochrane Collaboration. Cochrane Library Database of Systematic Reviews 2015. Complementary medicine and alternative medicine. John Wiley \& Sons, Ltd.; 2015. Online: http://www.cochranelibrary.com/ topic/Complementary\%20\%26\%20alternative\%20medicine/Cancer/? page $=1$; last access: 30.11 .2015

39 Bardia A, Barton DL, Prokop LJ et al. Efficacy of complementary and alternative medicine therapies in relieving cancer pain: a systematic review. J Clin Oncol 2006; 24: 5457-5464

40 Roberts $\mathrm{H}$. Safety of herbal medicinal products in women with breast cancer. Maturitas 2010; 66: 363-369

41 Han E, Johnson N, Delamelena $T$ et al. Alternative therapy used as primary treatment for breast cancer negatively impacts outcomes. Ann Surg Oncol 2011; 18: 912-916

42 Hutt N, Kopferschmitt-Kubler M, Cabalion J et al. Anaphylactic reactions after therapeutic injection of mistletoe (Viscum album L.). Allergol Immunopathol (Madr) 2001; 29: 201-203

43 Horneber MA, Bueschel G, Huber R et al. Mistletoe therapy in oncology. Cochrane Database Syst Rev 2008; 2: CD003297

44 Mathijssen RH, Verweij J, de Bruijn P et al. Effects of St. John's wort on irinotecan metabolism. J Natl Cancer Inst 2002; 94: 1247-1249

45 Musial F, Bussing A, Heusser P et al. Mindfulness-based stress reduction for integrative cancer care: a summary of evidence. Forsch Komplementmed 2011; 18: 192-202

46 Cramer H, Lauche R, Paul A et al. Mindfulness-based stress reduction for breast cancer-a systematic review and meta-analysis. Curr Oncol 2012; 19: e343-e352

47 Chang TW. Letter: Activation of cutaneous herpes by acupuncture. N Engl J Med 1974; 291: 1310

48 Cheng TO. Infective endocarditis, cardiac tamponade, and AIDS as serious complications of acupuncture. Arch Intern Med 2004; 164: 1464

49 Cheng TO. Cardiac tamponade following acupuncture. Chest 2000; 118 : 1836-1837

50 Cheng TO. Acupuncture and acquired immunodeficiency syndrome. Am J Med 1989; 87: 489

51 Chen TZ, Wu JC, Yen FS et al. Injection with nondisposable needles as an important route for transmission of acute community-acquired hepatitis C virus infection in Taiwan. J Med Virol 1995; 46: 247-251

52 Chen FP, Hwang SJ, Lee HP et al. Clinical study of syncope during acupuncture treatment. Acupunct Electrother Res 1990; 15: 107-119

53 Chen CY, Liu GC, Sheu RS et al. Bacterial meningitis and lumbar epidural hematoma due to lumbar acupunctures: a case report. Kaohsiung J Med Sci 1997; 13: 328-331

54 Cho YP, Jang HJ, Kim JS et al. Retroperitoneal abscess complicated by acupuncture: case report. J Korean Med Sci 2003; 18: 756-757

55 Tseng HS, Chan SE, Kuo SJ et al. Acupuncture-related rapid dermal spread of breast cancer: a rare case. J Breast Cancer 2011; 14: 340-344
56 Dodin S, Blanchet C, Marc I et al. Acupuncture for menopausal hot flushes. Cochrane Database Syst Rev 2013; 7: CD007410

57 Walker EM, Rodriguez AI, Kohn B et al. Acupuncture versus venlafaxine for the management of vasomotor symptoms in patients with hormone receptor-positive breast cancer: a randomized controlled trial. J Clin Oncol 2010; 28: 634-640

58 Saper RB, Kales SN, Paquin J et al. Heavy metal content of ayurvedic herbal medicine products. JAMA 2004; 292: 2868-2873

59 Webster GJ, Hallett R, Whalley SA et al. Molecular epidemiology of a large outbreak of hepatitis B linked to autohaemotherapy. Lancet 2000; 356: 379-384

60 Zuzak TJ, Rauber-Luthy C, Simoes-Wust AP. Accidental intakes of remedies from complementary and alternative medicine in children-analysis of data from the Swiss Toxicological Information Centre. Eur J Pediatr 2010; 169: 681-688

61 Hietala $M$, Henningson $M$, Ingvar $C$ et al. Natural remedy use in a prospective cohort of breast cancer patients in southern Sweden. Acta Oncol 2011; 50: 134-143

62 Kang E, Yang EJ, Kim SM et al. Complementary and alternative medicine use and assessment of quality of life in Korean breast cancer patients: a descriptive study. Support Care Cancer 2012; 20: 461-473

63 Ahn WS, Yoo J, Huh SW et al. Protective effects of green tea extracts (polyphenon E and EGCG) on human cervical lesions. Eur J Cancer Prev 2003; 12 : 383-390

64 Zhang $D$, Al-Hendy $M$, Richard-Davis $G$ et al. Green tea extract inhibits proliferation of uterine leiomyoma cells in vitro and in nude mice. Am J Obstet Gynecol 2010; 202: 289

$65 \mathrm{Kim}$ YW, Bae SM, Lee JM et al. Activity of green tea polyphenol epigallocatechin-3-gallate against ovarian carcinoma cell lines. Cancer Res Treat 2004; 36: 315-323

66 Kakuta Y, Nakaya N, Nagase S et al. Case-control study of green tea consumption and the risk of endometrial endometrioid adenocarcinoma. Cancer Causes Control 2009; 20: 617-624

67 Dobos GJ. [20 years Research Complementary Medicine: the path from avant garde to mainstream]. Forsch Komplementmed 2013; 20: 10-12

68 Lee C, Raffaghello L, Brandhorst S et al. Fasting cycles retard growth of tumors and sensitize a range of cancer cell types to chemotherapy. Sci Transl Med 2012; 4: 124ra27

69 Safdie FM, Dorff T, Quinn D et al. Fasting and cancer treatment in humans: a case series report. Aging (Albany NY) 2009; 1: 988-1007

70 Smith LA, Azariah F, Lavender VT et al. Cannabinoids for nausea and vomiting in adults with cancer receiving chemotherapy. Cochrane Database Syst Rev 2015; 11: CD009464

71 NCCAM. NCCAM-funded studies in PubMed. 2014. Online: http:// nccam.nih.gov/research/results; last access: 30.11 .2015

$72 \mathrm{NIH}$. Grants \& Funding. 2014. Online: http://grants.nih.gov/grants/ financial/index.htm\#Res14; last access: 30.11.2015 